\title{
Zona de sutura e organização do Orógeno Ribeira Setentrional
}

\author{
Mario Jorge Gesteira Fonseca ${ }^{1 *}$, Julio Cesar Mendes², Zenaide Carvalho Gonçalves da Silva ${ }^{3}$, \\ Jorge Costa de Moura ${ }^{2}$
}

\begin{abstract}
Resumo O Orógeno Ribeira Setentrional (Neoproterozoico/Cambriano), que se estende da Baía de Guanabara até o paralelo 20, engloba parte dos Estados do Rio de Janeiro, Minas Gerais e Espírito Santo e é constituído de três zonas bem distintas. De noroeste a sudeste, a primeira é designada de Zonas Externas do Sudeste Mineiro, que exibem extenso embasamento, de rochas arqueanas e paleoproterozoicas, sobre o qual se encontram rochas metassedimentares brasilianas, dominantemente alóctones. A zona seguinte, designada de Zonas Internas, é limitada aos Estados do Rio de Janeiro e Espírito Santo. Contém mais de $80 \%$ das rochas magmáticas brasilianas, tendo experimentado metamorfismo de tipo Abukuma, acompanhado por extensa anatexia, não constatada nas outras duas zonas, e é a mais importante zona do orógeno. As Zonas Externas do Sudeste Mineiro são separadas das Zonas Internas pela Zona de Sutura, que contém um conjunto de rochas metamáficas e metaultramáficas com $22 \mathrm{~km}$ de extensão, e que apresentam assinatura geoquímica de toleiítos de crosta oceânica. As Zonas Externas de Cabo Frio constituem a terceira zona e se situam na extremidade sudeste do Estado do Rio de Janeiro. São formadas por um embasamento paleoproterozoico, sobre o qual se encontram restos de rochas metassedimentares brasilianas. São destituídas de rochas magmáticas brasilianas, não tendo havido na região qualquer orogênese posterior à brasiliana. A geologia da região evidencia o desenrolar das últimas etapas do Ciclo de Wilson.
\end{abstract}

Palavras-chave: zonas constitutivas do orógeno; segmentos da zona de sutura; diferenças entre as várias zonas do orógeno.

Abstract Suture zone and organization of the Northern Ribeira Orogen. The Northern Ribeira Orogen (Neoproterozoic/Cambrian), which is extended from Guanabara Bay to the $20^{\text {th }}$ parallel, includes part of the States of Rio de Janeiro, Minas Gerais and Espírito Santo, and consists of three distinct zones. From northwest to southeast, the first is designated as External Zones of Mineiro Southeast, exhibiting extensive basement and being formed by Archean and Paleoproterozoic rocks, comprising braziliano metasedimentary rocks, dominantly allochtonous. The next zone, called Internal Zones, is limited to the States of Rio de Janeiro and Espírito Santo. They contain over $80 \%$ of the braziliano magmatic rocks, having experienced Abukuma type metamorphism, accompanied by intense anatexis, which was not identified in the other two zones, and it is the most important zone of the orogen. The External Zones of the Mineiro Southeast are separated from the Internal Zones by the Suture Zone, which contains a set of meta-mafic and meta-ultramafic rocks of $22 \mathrm{~km}$ long, with geochemical signature of tholeiitic oceanic crust. The External Zones of Cabo Frio constitute the third one and are located in the southeast corner of the State of Rio de Janeiro. They are formed by a Paleoproterozoic basement, containing remains of braziliano metasedimentary rocks. They lack braziliano magmatic rocks, and there was no sign of later orogeny after the braziliano one. The geology of the region evidences the development of the last steps of Wilson's Cycle.

Keywords: constitutive zones of the orogen; segments of the suture zone; differences between the various zones of the orogen.

INTRODUÇÃOO O segmento setentrional do Orógeno Ribeira, que se estende da região Central do Rio de Janeiro até o paralelo 20, é a parte mais desconhecida do cinturão orogênico, que Almeida F.F.M. et al. (1973) designaram de Faixa Ribeira, formado no intervalo Neoproterozoico/Cambriano.

O presente trabalho, que trata da tectônica desse segmento, engloba parte dos Estados do Rio de
Janeiro, Espírito Santo e Minas Gerais. A área objeto do estudo limita-se a oeste pelo meridiano da Baía de Guanabara, ao norte pelo paralelo 20, a leste e ao sul pela faixa costeira.

A interpretação tectônica de uma vasta região implica, necessariamente, em um entendimento consistente da estratigrafia, das estruturas e do magmatismo regionais e de um volume considerável de dados

\footnotetext{
${ }^{1}$ Departamento Nacional de Produção Mineral - DNPM, Ministério de Minas e Energia - MME, Rio de Janeiro (RJ), Brasil. E-mail: mjgfonseca@uol.com.br

${ }^{2}$ Instituto de Geociências, Universidade Federal do Rio de Janeiro - UFRJ, Rio de Janeiro (RJ), Brasil. E-mail: julio@geologia.ufrj.br, jcmoura@cnen.gov.br

${ }^{3}$ Faculdade de Ciências e Tecnologia, Universidade Nova de Lisboa, Centro de Investigação em Ciência e Engenharia Geológica CICEGe, Departamento de Ciências da Terra, Caparica, Portugal. E-mail: zcs@fct.unl.pt

*Autor correspondente
} 
petrológicos, geocronológicos e geoquímicos, sem os quais a interpretação tectônica não se realiza a contento.

As atividades de mapeamento geológico executadas no território fluminense no século 20, levadas a efeito por diversos órgãos governamentais e por uma multiplicidade de empresas e autores, revelaram feições até então desconhecidas. Mas, por uma série de fatores, como a ausência de instrumental teórico para resolver os complexos problemas da geologia regional, a baixa densidade dos trabalhos de campo posteriores e as modificações das designações do conteúdo litológico e dos limites das supostas 'unidades' estabelecidas anteriormente, parte considerável desses mapeamentos deixaram grandes lacunas de conhecimento geológico. Como consequência, o conhecimento geológico do território fluminense permaneceu atrasado e tem continuado como um desafio técnico e intelectual a todos os que se dedicam à geologia da região. Assim, autores que se propunham a produzir trabalhos geológicos sobre a região não dispunham de dados consistentes nos quais pudessem se apoiar.

Além disso, os termos 'Paraíba' e 'Paraíba do Sul' já foram usados como série, grupo, associação e complexo, tendo cada autor utilizado critérios distintos para o agrupamento dos litotipos.

Assim, as diversas versões sobre o que é o Complexo Paraíba do Sul (CPS) são divergentes significativamente entre os pesquisadores, não se conhecendo uma definição única e aceitável para a maioria.

Posteriormente, pesquisadores que faziam referências ao suposto CPS davam-lhe sua interpretação particular. Entre outros, Campos Neto \& Figueiredo (1990) definiram-no como uma sequência supracrustal neoproterozoica, que apresentaria incompatibilidade metamórfica com os terrenos adjacentes. Cordani et al. (1973), datando gnaisses e rochas charnockíticas da região entre o Rio de Janeiro e Minas Gerais, concluíram que "A Formação Juiz de Fora possui as mesmas características petrológicas que a Formação Paraíba do Sul, e esta teria se formado no ciclo Transamazônico". Brandalise et al. (1976) definiram como pertencendo ao CPS os gnaisses e migmatitos compreendidos entre a costa do Estado do Rio de Janeiro e a Serra da Mantiqueira.

Não se trata aqui de fazer crítica aos pesquisadores, mas de constatar que inexiste qualquer consenso a respeito do que seja o CPS, da sua idade, constituição, área de ocorrência, critérios de distinção e de suas relações com outros conjuntos litológicos. Disto, decorre que a expressão Complexo
Paraíba do Sul não pode ser tomada para designar qualquer unidade ou conjunto litológico.

O que se deseja dizer é que muitas proposições contidas na literatura geológica da região nem sempre foram construídas a partir de um conjunto consistente de dados de campo, mas, com frequência, correspondem a modelos ou concepções evolutivas previamente imaginadas, que visavam preencher os espaços vazios do conhecimento geológico, não raro assumindo a presunção tácita de verdade já demonstrada.

Dessa forma, compreende-se que este trabalho tenha a necessidade de discutir algumas proposições contidas na literatura geológica regional, assumindo uma postura crítica em relação à mesma para tentar alcançar o objetivo principal, que é o estabelecimento das conexões do particular com o geral, das estruturas com a evolução tectônica.

O presente trabalho foi iniciado com o estudo de mapas geofísicos da região (CPRM 1978) e sua posterior comparação com os mapas geológicos. Disto resultou a confirmação de algumas feições geológicas conhecidas, e a localização mais precisa do conjunto de rochas máficas e ultramáficas metamorfizadas, que têm assinatura geoquímica de toleiítos de fundo oceânico, que se situam dentro da Zona de Sutura.

A grande dificuldade de acesso a esse conjunto de rochas e a não execução dos trabalhos geológi$\cos$ de detalhe ao norte e ao noroeste de São João do Paraíso, que demandariam procedimentos incompatíveis com as limitações deste estudo, constituíram-se como fatores limitantes para o esclarecimento mais detalhado da Zona de Sutura.

Os estudos petrográficos e as análises geoquímicas foram executados no Laboratório de Fluorescência de Raio X, do Instituto de Geociências da Universidade Federal do Rio de Janeiro (UFRJ). As análises dos elementos terra rara (ETR) foram realizadas no laboratório LAKEFIELD- GEOSOL.

\section{PRINCIPAIS ZONAS DE CISALHAMENTO DA REGIÃO O conhecimento das zonas de cisa-} lhamento da região é muito desigual, mas é imprescindível para o entendimento da evolução tectônica regional. Serão referidas no presente trabalho apenas as principais, embora possam estar representadas outras (Fig. 1).

Lamego (1936) foi quem primeiro observou que o Rio Paraíba do Sul médio-inferior se encaixa em uma estruturação singular, que exibe disposição 


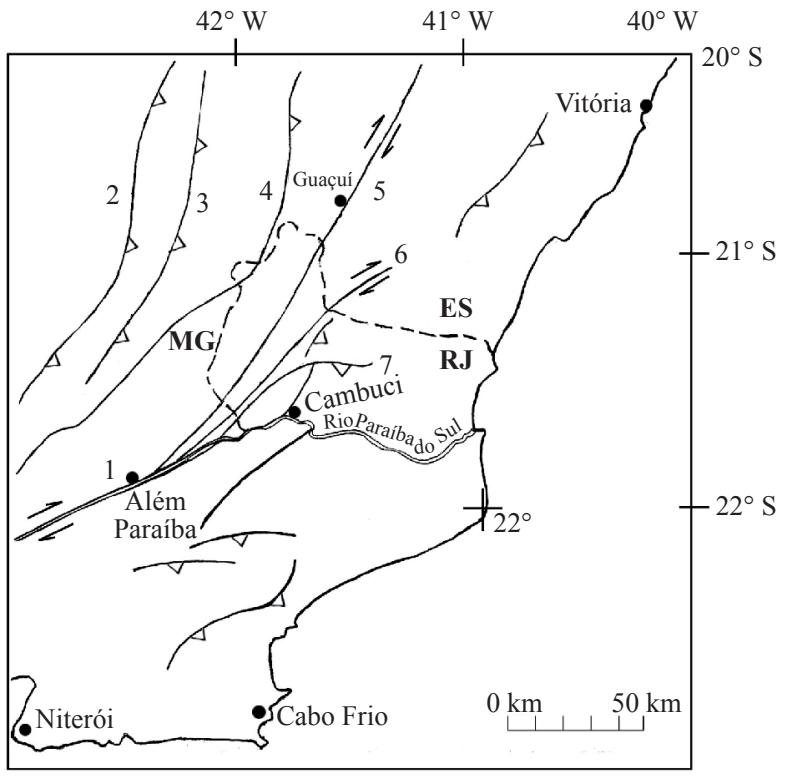

Figura 1 - As principais zonas de cisalhamentoda região: (1) Z.C. do Rio Paraíba do Sul; (2) Z.C. de Guiricema; (3-4) Z.Cs sem designação formal; (5) Z.C. de Guaçui; (6) Z.C. de Bom Jesus de Itabapoana; (7) Z.C. de São João do Paraíso.

quase simétrica dos mergulhos de suas estruturas planares para o centro, como em um sinforme. Constatou, também, que tal estruturação não se restringia ao estrito vale do rio, mas apresentava uma largura que se estendia do litoral fluminense até o sopé da Serra da Mantiqueira. Considerou-a um grande sinclinal. Ebert (1968) a definiu como 'divergência em forma de leque' e Almeida et al. (1975) classificaram-na como uma zona de cisalhamento dúctil, dextral. Campanha (1980) corroborou tal afirmativa e constatou que essa zona é constituída de rochas de textura milonítica e blastomilonítica e recristalização sintectônica, com foliação vertical e subvertical em sua zona central, e lineação de estiramento sub-horizontal. Afirmou, ainda, que a mesma teve uma evolução polifásica, e mostrou a transposição de estruturas mais antigas por outras mais novas. As dobras existentes, de pequenas dimensões, exibem marcante paralelismo com a direção da zona de cisalhamento, tendo constatado também encurtamento perpendicular à zona milonítica principal. A presença de blastomilonitos migmatizados levou Campanha (1980) a admitir que a implantação da Zona de Cisalhamento do Rio Paraíba do Sul (ZCRPS) foi, em parte, anterior à anatexia crustal brasiliana, e que a migmatização ocorreu simultaneamente a uma intensa transposição.

Oliveira (1983) constatou que a ZCRPS é formada por migmatitos cinzentos, dominantemente estromáticos, que passam a gnaisses finamente bandados na parte central, como resultado da forte transposição que sofreram. $\mathrm{O}$ mesmo autor afirmou, ainda, que: "a característica mais marcante dessas rochas é a cataclase com recristalização, levando à formação de tipos blastomiloníticos". Dayan \& Keller (1990) sugeriram a presença de duas zonas miloníticas paralelas e uma simetria de estruturas em relação à zona central de deformação.

Corrêa Neto et al. (1994) observaram o predomínio de movimentos transcorrentes dextrais, assim como a existência de movimentos verticais de blocos na zona central, que fizeram com que fatias de rochas charnockíticas tivessem sido tectonicamente alçadas entre paragnaisses. Machado \& Endo. (1993) postularam que a parte central da zona de deformação representa o eixo de uma estrutura-em-flor-positiva, como decorrência da transpressão entre os dois blocos crustais que ela separa, o que é também endossado pelo presente trabalho. Carneiro et al. (1996) afirmaram que "a justaposição tectônica de litologias distintas inibe um mapeamento geológico stricto senso, e não pode comportar quaisquer considerações de ordem estratigráfica".

A ZCRPS apresenta-se muito mais larga e mais importante na região de Além Paraíba, onde exibe níveis crustais mais profundos e faz sua inflexão, de ENE para NNE, transformando-se na Zona de Cisalhamento de São João do Paraíso (ZCSJP).

Heilbron et al. (1991) designaram a ZCRPS de Megassinforma do Paraíba do Sul, que teria sido estruturada durante a fase de deformação D-3, e cuja zona de charneira seria caracterizada por uma sucessão de sinformes e antiformes. O flanco noroeste da referida estrutura seria constituído pelos 'domínios' Andrelândia, Juiz de Fora e Paraíba do Sul, e tal 'ordenamento' se repetiria no flanco sudeste, com o acréscimo do Complexo Piedade.

Tal interpretação não parece adequada, uma vez que, ao mesmo tempo, simplifica e distorce a compreensão das deformações que se deram ao longo da ZCRPS, o que é decisivo para o entendimento da evolução tectônica da região.

A formação de um sinforme ocorre por flexão, e não por cisalhamento e recristalização, como foi amplamente observado e descrito pela quase totalidade dos pesquisadores ao longo de toda a ZCRPS. Ebert et al. (1991) resumiram, de forma precisa, que "o Cinturão Transpressivo do Rio Paraiba do Sul é o produto da deformação regional progressiva, não co-axial, 
não plana, heterogênea e dextral, que proporcionou segmentação das unidades litológicas regionais".

Ao norte da região estudada, as zonas de cisalhamento formam um conjunto bem aberto, que se afunila para o sudoeste (Fig. 1), tendendo a tangenciar a ZCRPS na região de Além Paraíba. Tal disposição indica muito provavelmente um vínculo genético entre essas zonas e a ZCRPS. Talvez tenha contribuído para tal a influência do vetor de deslocamento das duas placas, a Sanfranciscana e a do Oeste do Congo.

No território mineiro, uma das mais importantes é a Zona de Cisalhamento de Guiricema (Brandalise et al. 1976), que se situa a Oeste de todas as outras e se apresenta com uma extensão talvez maior que $200 \mathrm{~km}$, definindo o limite aproximado entre os domínios Barbacena, a noroeste, e Juiz de Fora, a leste, e é acompanhada por 'lineamentos' de grande extensão. Em sua parte meridional, logo a oeste de Juiz de Fora, mostra-se como um cavalgamento de médio a baixo ângulo de mergulho.

As duas zonas, que se situam a leste da anterior, sem designação formal, são cavalgamentos menos extensos, de médio a baixo ângulo, com vergência para NW e subparalelas à anterior.

Mais a leste, situa-se a Zona de Cisalhamento de Guaçuí (ZCG), que é uma das mais importantes descontinuidades crustais do sudeste brasileiro. Tem extensão aproximada de $240 \mathrm{~km}$. Trata-se de uma zona transcorrente dextral, que se apresenta desde Afonso Cláudio, ao sul do paralelo 20, quase retilínea ao atravessar parte dos territórios dos Estados do Espírito Santo, Rio de Janeiro e Minas Gerais até a região de Além Paraíba, onde se dispõe, também tangenciando a ZCRPS. Exibe, na região de Guaçuí, uma faixa de até $4 \mathrm{~km}$ de largura, constituída dominantemente por gnaisses miloníticos e blastomilonitos, com foliação cataclástica verticalizada ou com forte mergulho para o sudeste. Ao sul, essa zona passa próxima às cidades de Santo Antonio de Pádua e Miracema, exibindo mergulhos de até $75^{\circ}$ para sudeste. Além disso, em toda a sua extensão, é acompanhada por uma grande quantidade de corpos máficos, sugerindo que eles podem ter um vínculo genético com a referida estrutura.

A Zona de Cisalhamento de Bom Jesus de Itabapoana (ZCBJI) foi originalmente nomeada por Brenner et al. (1980) de Zona de Cisalhamento de Baltazar, mas é ao Sul da cidade de Bom Jesus de Itabapoana que está bem característica e se mostra com sua maior espessura e verticalidade. Trata-se de uma zona transpressiva dextral, que é verticalizada em grande parte da sua extensão.

A Zona de Cisalhamento de São João do Paraíso (ZCSJP) foi assim designada por Batista et al. (1977), e passa na localidade que lhe empresta o nome. Esta zona é, a rigor, a continuidade física para Nordeste da parte central da ZCRPS, mas não sua continuidade estrutural, fato ainda não relatado na literatura geológica da região. Trata-se de uma zona de cisalhamento muito verticalizada e com direção NNE em sua parte sudoeste, mas a nordeste apresenta-se com sinuosidade para ENE, que não pode ser observada nas outras zonas. Portanto, sua geometria é única.

O que é muito comum na maioria destas zonas de cisalhamento é a partição da deformação, e o conjunto dos dados leva à conclusão de que os campos de esforços criados durante a Orogênese Brasiliana variaram localmente, e não se pode concordar que tenha havido apenas uma convergência frontal seguida de uma outra oblíqua, ou vice-versa; a convergência foi sempre oblíqua, menos oblíqua ao norte e mais ao sul.

ZONA DE SUTURA DO ORÓGENO A Zona de Sutura (ZS) do orógeno é uma megafeição tectônica, que não se mostra uniforme e, aparentemente, nem mesmo contínua. Essa zona configura-se como um extenso front de deformação, exibindo grande complexidade estrutural e petrológica e separando dois compartimentos litosféricos que tiveram evoluções geológicas e propriedades reológicas radicalmente distintas.

Da região oeste do Estado do Rio de Janeiro para Nordeste, até o paralelo 20, pelas suas singularidades, a zona pode ser dividida em quatro segmentos (Fig. 2); embora entre eles não haja mudanças bruscas, mas apenas disposições estruturais e litologias diferenciadas.

O primeiro segmento é a ZCRPS, referida por diversos pesquisadores, que se estende do oeste fluminense até a região de Itaocara. O segundo estende-se dessa última região para nordeste, até a região de São João do Paraíso. A partir desta última localidade, a ZCSJP faz uma inflexão para ENE e desenvolve um trecho sinuoso, inexistente nas outras zonas, indicando uma modificação tectônica significativa, que pode definir o terceiro segmento da ZS, mas que seria o menor e o mais complexo entre os quatro. O quarto segmento é representado pela ZCG, em sua porção setentrional, onde situa-se a cidade homônima de Guaçuí (Fig. 2). 


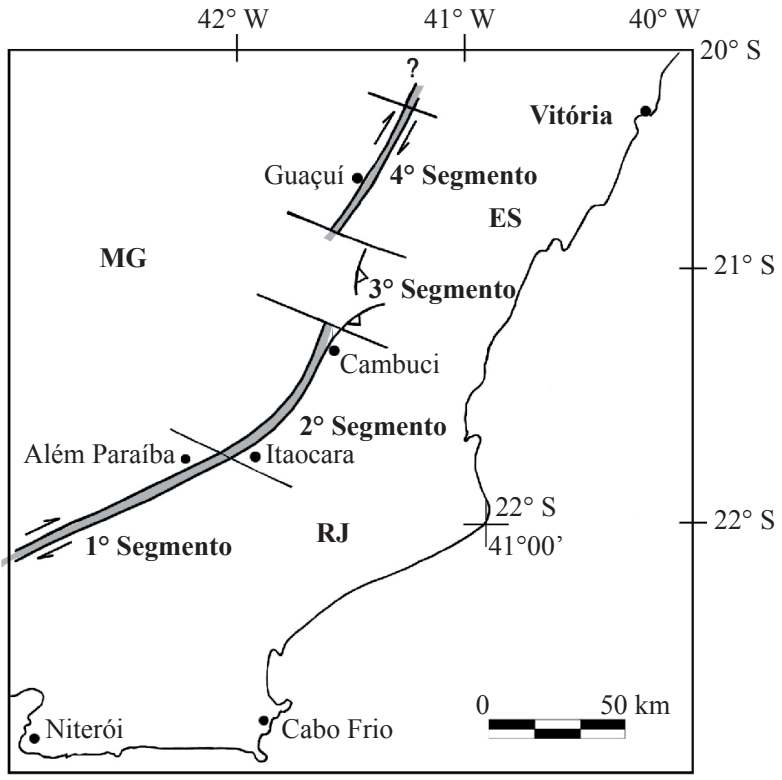

Figura 2-A Zona de Sutura e seus quatro segmentos.

O primeiro pesquisador que percebeu a existência de dois blocos crustais distintos, separados pela ZCRPS, foi Campanha (1980), ao observar as amostras datadas e posteriormente tratadas pelo método isocrônico, constatou que as do bloco norte se situavam em isócronas transamazônicas ou mais antigas, enquanto nas do bloco sul não foram encontradas amostras que se situassem acima da isócrona brasiliana. E explicitou: "Estes dados sugerem que o lineamento de Além Paraíba separa blocos com diferentes padrões radiométricos".

No seu primeiro trecho a ZS é representada pela ZCRPS, que é bem conhecida em termos estruturais e petrológicos, apresenta largura aproximada de até $5 \mathrm{~km}$ em sua parte mais larga e exibe uma grande e inusitada mistura, em escalas macro e micro, de rochas neoproterozoicas e paleoproterozoicas, intensamente deformadas, como citado por diversos autores.

Levando-se em conta os resultados dos trabalhos desses autores, torna-se muito difícil entender a ZCRPS, sem que se admita também a existência de dois blocos crustais distintos, que colocaram justapostas rochas de diferentes tipos, idades, origens e dimensões, mas com deformações similares ao seu longo.

O segundo segmento da ZS, que fica entre a região de Itaocara até imediatamente ao norte de São João do Paraíso, é onde essa zona está bem típica, apresentando-se com largura máxima de até $8 \mathrm{~km}$, que vai de Cambuci à localidade de Monte Verde, sendo limitada a oeste pela ZCSJP.
Dentro deste segmento, ocorrem litotipos das unidades Italva e São Fidélis, tais como biotita-gnaisses, calcissilicáticas, anfibolitos, mármores, rochas manganesíferas, kinzigitos, raros quartzitos e meta-cherts, além de rochas de menor grau metamórfico, as quais provavelmente representem um metamorfismo retrógrado; granulitos ocorrem com pouca frequência, mas sem que se saiba sua idade. Também foram identificados quatro corpos restritos de rochas granitoides, parcialmente deformados e representáveis apenas em escala de detalhe, sendo que um deles passa a charnockito.

Assim, as litologias presentes neste local não constituem um conjunto que possa ser considerado como unidade ou associação litológica, o que ocorre também na ZCRPS.

Nesse segmento, as deformações e o metamorfismo das rochas metassedimentares brasilianas se deram em níveis crustais mais diversos e, em parte, menos profundos do que no segmento anterior. Por outro lado, as atividades metamórfica e magmática dentro dele foram diversificadas e podem ser referidas ou associadas ao que Coleman (1977) designou de 'metamorfismo interno', que corresponde a um metamorfismo próprio das zonas de sutura.

Sob o ponto de vista estrutural, observou-se que os kinzigitos e as calcissilicáticas, quando estão nas partes mais altas da dorsal, apresentam mergulhos relativamente suaves, entre $30^{\circ}$ e $40^{\circ}$ para leste-sudeste, e se colocam tectonicamente sobre as litologias citadas. Assim, é possível dizer que houve uma superposição diacrônica de dois campos de esforços distintos: um, mais antigo, que formou as zonas de cisalhamento transpressivas, verticalizadas, que limitam lateralmente a oeste a ZS, e outro que empurrou as supracrustais brasilianas de SE para NW.

Este trecho da ZS separa, de forma bem clara, dois compartimentos crustais, que tiveram evoluções geológicas distintas em termos estruturais, petrológicos e magmáticos: o compartimento a oeste representa a páleo-margem do Oceano Adamastor e é formado por um embasamento do Complexo Juiz de Fora, sobre o qual encontram-se rochas das unidades Italva e São Fidélis, que estão alóctones; enquanto a leste da ZS, situam-se as litologias típicas das Zonas Internas do orógeno, onde se deram, com grande intensidade, os processos de metamorfismo, anatexia, fusão crustal e espessamento de crosta.

É também neste segmento da ZS que se situa o conjunto de rochas metamáficas e metaultramáficas, que apresentam assinatura geoquímica de 
toleiítos de fundo oceânico. Ocorrem entre Cambucí, a leste, e São João do Paraíso e Monte Verde, a oeste. Foram postas em evidência por Mendes e Fonseca et al. (2011). Tais rochas se situam entre as localidades de São João do Paraíso, Cambucí e Monte Verde. Compõem uma forma triangular imperfeita, com vértice mais agudo exatamente ao norte de São João do Paraíso; seu lado oriental se estende deste ponto até $2 \mathrm{~km}$ ao sul de Cambuci, próximo à ponte sobre o rio Paraíba, perfazendo aproximadamente $22 \mathrm{~km}$, embora sem a certeza de sua inteira continuidade. Seu lado ocidental se estende de São João do Paraíso até Monte Verde, perfazendo aproximadamente $13 \mathrm{~km}$.

São gabros, gabronoritos, gabros cumuláticos, piroxenitos, basaltos, dioritos (minoritários), variavelmente metamorfisados e deformados. Os gabros cumuláticos, que se situam dentro e nas proximidades de Monte Verde, são os litotipos que se apresentam menos deformados e metamorfisados. Os estudos geoquímicos levados a efeito por Mendes et al. (2011) indicaram que são toleiítos de fundo oceânico, com elevados e variáveis teores de $\mathrm{Fe}_{2} \mathrm{O}_{3}$ e $\mathrm{MgO}$, baixos a médios valores totais em álcalis e valores altos a anômalos em $\mathrm{Cr}$ e Ni.

Também foram identificadas entre Cambuci e Monte Verde estruturas decompostas, que apresentam formas almofadadas e tubulares e que podem ser interpretadas como lavas de fundo oceânico (Fig. 3).

Por fim, o trecho da ZC, entre Cambucí e Monte Verde, exibe uma diversidade litológica muito mais acentuada do que a da ZCRPS, enquanto suas zonas de cisalhamento são menos frequentes e acentuadas e seu arranjo estrutural é muito diferente dos terrenos adjacentes que ficam a leste e oeste. Portanto, existem indicadores geofísicos, geoquímicos, tectônicos e geocronológicos que convergem para indicar a existência de dois grandes blocos crustais, separados por uma ZS, levando-se em conta os dados obtidos por Campanha (1980) e Mendes et al. (2011).

O traçado do terceiro segmento da ZS, que se situa ao Norte de São João do Paraíso, é de difícil precisão. Entretanto, há uma grande probabilidade de que a ZS possa ser delineada neste local, mas com uma quantidade bem maior de trabalhos de detalhe e de procedimentos geocronológicos, que não puderam ser desenvolvidos.

Mas, as atividades de campo executadas na região revelaram que as rochas supracrustais brasilianas da Unidade Italva, que, neste ponto, são majoritárias, estão, em algumas áreas, claramente misturadas ou englobando granulitos, enderbitos, farsunditos, jotunitos, que são litotipos típicos do Complexo Juiz de Fora, além de gnaisses de grau alto, com ortoclásio e sillimanita, que geralmente exibem direções para o quadrante NW-SE e mergulhos baixos a moderados para NE.

Tais misturas ocorrem a sudeste de Bom Jesus de Itabapoana, ao sul e a leste da localidade de Carabuçu, não tendo sido possível traçar seus limites e estabelecer suas relações com as rochas brasilianas. No mapa geológico do Departamento de Recursos Minerais do Rio de Janeiro (DRM) da Folha Italva (Batista et al. 1977) existem três unidades (Monte Verde, São João do Paraíso e Vista Alegre), que comportam tais misturas.

Tupinambá \& Trouw (1994) descreveram a ocorrência, ao norte de Italva, de gnaisses e granulitos, com paragênese de ortopiroxênio + clinopiroxênio + plagioclásio, que teriam sofrido 'dois picos metamórficos distintos no tempo, com diferentes regimes de pressão' e com direção NW-SE e
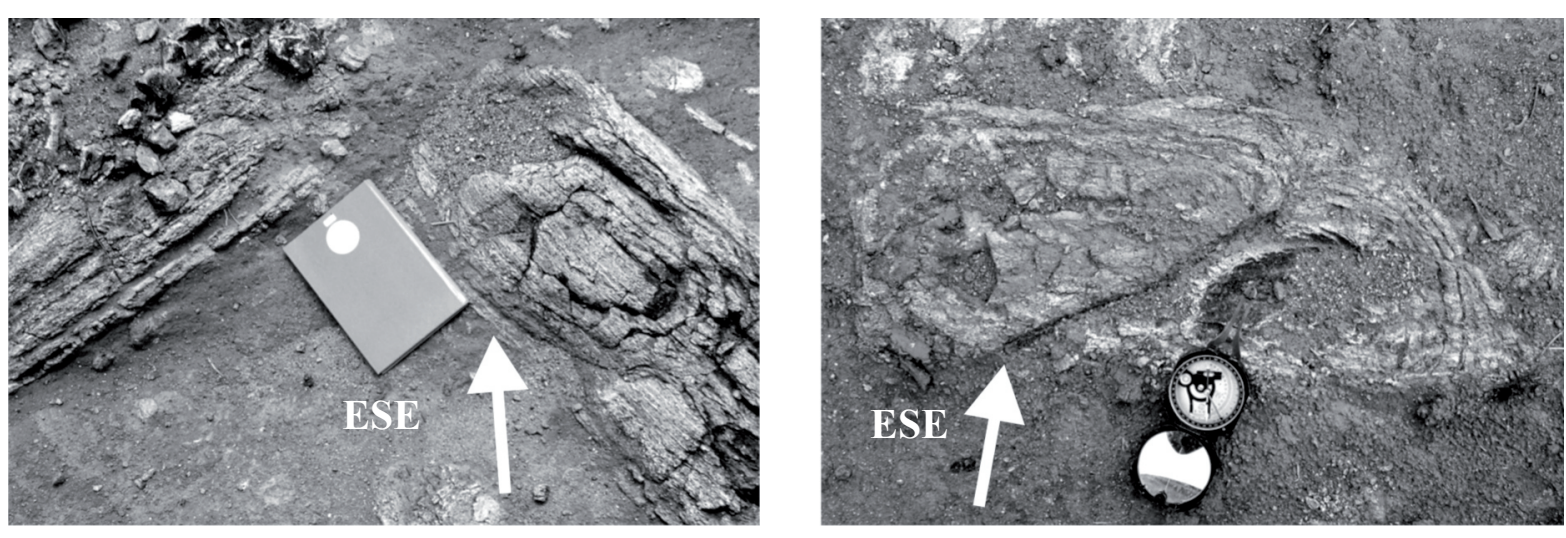

Figura 3 - Fotos de estruturas em almofada e tubular, em rochas de fundo oceânico, muito decompostas, estrada Cambuci - Monte Verde. 
mergulhos para NE, aos quais eles atribuíram uma idade brasiliana.

Tais rochas, como referidas, não podem ser tomadas como brasilianas, uma vez que diferem destas em aspectos petrológicos e estruturais muito importantes. Elas muito provavelmente são anteriores ao metamorfismo brasiliano, pois, na região, as rochas supracrustais brasilianas não são granulitos, não havendo qualquer registro, em todos os trabalhos existentes, de que as rochas brasilianas tenham sofrido na região dois picos metamórficos distintos no tempo, com diferentes regimes de pressão. Além disso, se fossem brasilianas, o metamorfismo que as teria atingido seria mais amplo e mais fácil de ser identificado regionalmente.

Portanto, essas misturas de tipos litológicos brasilianos e pré-brasilianos não são detalhes localizados e independentes do restante, mas um fenômeno amplo, de caráter regional e origem tectônica, que ocorreu dentro e nas proximidades da ZS, e que deve ter uma explicação objetiva e compatível com as disposições tectônicas da região.

Esse conjunto de dados geológicos, em que algumas partes não combinam com o todo, quando confrontado com a geologia regional circundante, sugere fortemente a interpretação de que o referido segmento da ZCSJP, que faz uma inflexão de NNE para ENE, representa o limite Sul de uma pouco expressiva indentação tectônica, consequência de saliência na margem passiva da placa Sanfranciscana, mais antiga e mais fria, que teria se introduzido sob os metassedimentos da Unidade Italva, para fazer o ajuste entre os bordos das duas placas, o que teria causado a mistura de tipos litológicos brasilianos e pré-brasilianos, durante o processo de convergência e colisão entre tais placas. Mas, tal interpretação não se torna logo clara, e precisa ser referendada por mais trabalhos de detalhe e por datações radiométricas, pois o limite norte dessa provável indentação tectônica pode estar oculto.

Essa interpretação poderia ser invalidada se fosse provado que as rochas situadas entre o rio Itabapoana, ao norte, e o segmento ENE da ZCSJP, ao sul, fossem exclusivamente brasilianas, inclusive os granulitos, enderbitos, jotunitos etc, ou que tais misturas litológicas não existissem. Além disso, deveria também ser explicado porque a ZCSJP, que é a continuidade da ZCRPS, é verticalizada e de direção NNE em sua porção sudoeste, mas muda para ENE ao norte.
Considera-se como quarto segmento da ZS um trecho da ZCG, dentro do qual se encontra a cidade de Guaçuí. Embora pouco conhecido em seus detalhes, esse segmento se apresenta, na região, como uma faixa de 2 a $4 \mathrm{~km}$ de largura, formada, sobretudo, de milonitos e blastomilonitos, foliação cataclástica verticalizada ou com forte mergulho para o sudeste, e que termina logo ao sul do paralelo 20.

Esse trecho setentrional da ZS é muito semelhante às disposições encontradas no Estado do Rio de Janeiro, mas sem a complexidade da ZCRPS, que separa, com nitidez, dois blocos litosféricos com evoluções geológicas distintas. No caso da ZCG, esta zona controlou a mise-en-place do extensíssimo complexo granitoide sin ou tardicolisional de Muniz Freire, que, por ela é limitado a oeste, assim como a posição dos corpos magmáticos de Santa Angélica, Venda Nova e Afonso Cláudio, que se posicionam retilineamente paralelos à direção da ZCG.

A grande diversidade de aspectos em cada um dos segmentos da ZS faz lembrar a afirmativa de Dewey (1977), que não existe um padrão simples e único de sutura colisional.

Do exposto, pode-se dizer que a ZS marca uma flagrante assimetria entre os dois segmentos litosféricos que ela separa e que a colisão entre a Placa Sanfranciscana e a Placa do Oeste do Congo se configurou como uma superposição de eventos e processos geológicos diversificados e complexos, que se deram em diversos níveis crustais, e que o processo mais evidente da colisão, na região estudada, foi a fragmentação e mistura de litotipos dos mais diversos, brasilianos e pré-brasilianos, além de metamorfismo, recristalização e magmatismo, cujo estudo conjunto ainda está por ser feito.

ORGANIZAÇÃO DO ORÓGENO A formação de um orógeno é decorrência do encadeamento de diversos processos, tais como: fluxo de calor, mobilização de matéria, anatexia, magmatismo, metamorfismo e deformação crustal. Portanto, a distinção das zonas de um orógeno deve ser feita levando-se em conta, sobretudo, a importância dos quatro últimos processos (Fig. 4).

Um perfil que se estenda de Andrelândia (MG) até Cabo Frio (RJ) irá mostrar que o orógeno em pauta é constituído por três zonas distintas, como no orógeno Limpopo.

De noroeste para sudeste, a primeira é designada de Zonas Externas do Sudeste Mineiro (ZESM), 
que ocupam parte do sudeste mineiro e do sudoeste e norte fluminenses. A segunda zona, adjacente à anterior, é designada de Zonas Internas (ZI) e corresponde ao que foi nomeado por Fonseca et al. (1998) de Bloco Serra dos Órgãos, situado ao sul da ZCRPS e suas extensões para sudoeste e nordeste. Uma terceira zona, bem menor do que as duas outras, e presente apenas na extremidade sudeste do território fluminense, corresponde ao que foi nomeado por Fonseca (1998) de Bloco de Cabo Frio, e é designada de Zonas Externas de Cabo Frio (ZECF), como pode ser visto na Fig. 5.

As ZESM são marginais ao cráton do São Francisco, não havendo qualquer limite que marque a passagem entre zona móvel e cráton. Essas zonas se estendem, para o sul, até a ZCRPS, e para leste, até a ZCG, apresentando o mais extenso embasamento entre as três.

As ZESM são divididas em dois 'domínios' ou conjuntos litoestratigráficos separados pela Zona de Cisalhamento de Guiricema. O primeiro domínio, que fica a Noroeste, é constituído pelo Complexo Barbacena, formado de rochas arqueanas, máficas e ultramáficas, e de migmatitos de melanossomas máficos, por vezes comportando leucossoma granitoide (Oliveira 1983). A leste do anterior, situa-se o segundo 'domínio', constituído pelo Complexo Juiz de Fora, formado dominantemente por rochas da suíte charnockítica, de idade peleoproterozoica, composição intermediária e quimismo cálcio-alcalino (Oliveira 1983). Ainda, neste domínio, existem gnaisses e migmatitos de ocorrência esparsa, que não devem e não podem ser confundidos com os gnaisses e migmatitos brasilianos, enquanto que, ao norte de Itaperuna, ocorrem, esparsamente, corpos de anortosito, aparentemente não muito extensos, que não foram estudados. Assim, o Complexo Juiz de Fora não é formado exclusivamente de rochas da suíte charnockítica.

Sob o aspecto tectônico, os dois domínios são também distintos, indicando evoluções diferenciadas. No domínio Barbacena, as grandes nappes desenvolvem formas muito sinuosas, sobretudo a partir da região de Lima Duarte para NW; no domínio Juiz de Fora, ao contrário, predominam extensos cavalgamentos, a oeste, e grandes zonas de cisalhamento dúcteis dextrais, a leste (Fig. 1).

As rochas supracrustais brasilianas que ocorrem nas ZESM constituem, pelo menos, três grandes sequências alóctones. A primeira delas ocupa parte da região do sudeste mineiro, mas fora da área do presente

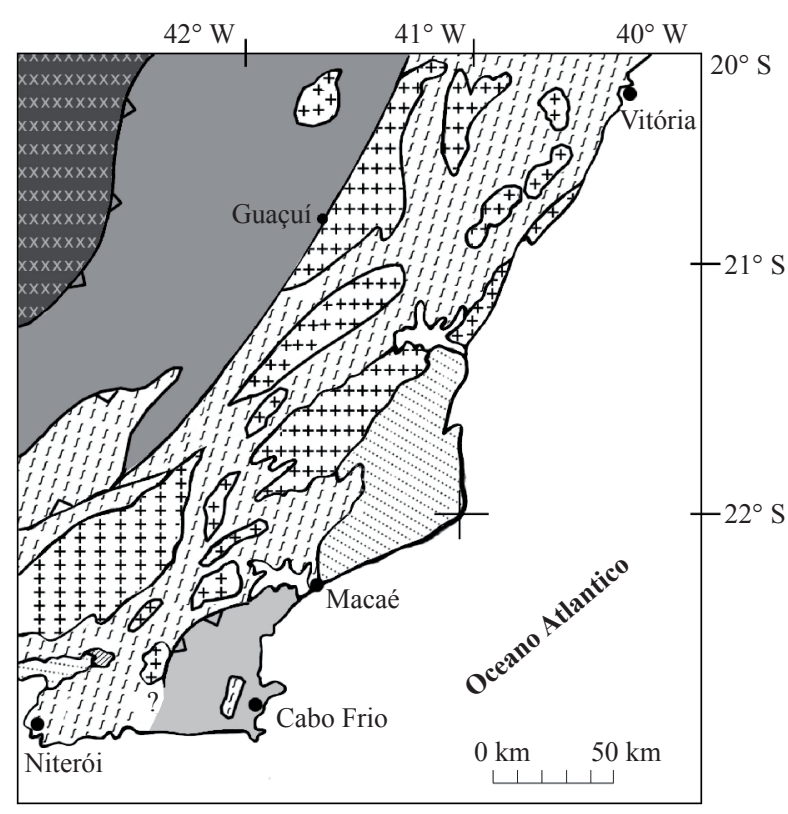

1. Sedimentos cenozoicos; 2. 2 Rochas alcalinas cretácico-terciárias;

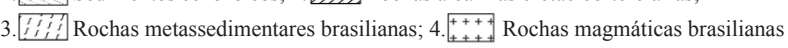
e diatexitos; 5. $\square$ Paleoproterozoico, Complexo Juiz de Fora; 6 . $\square$ Paleoproterozoico, Complexo Região dos Lagos; 7. $\begin{aligned} & x \times x \times x \\ & x \times x\end{aligned}$ Arqueano, Complexo Barbacena

Figura 4 - Mapa da distribuição dos conjuntos litoestratigráficos da região.

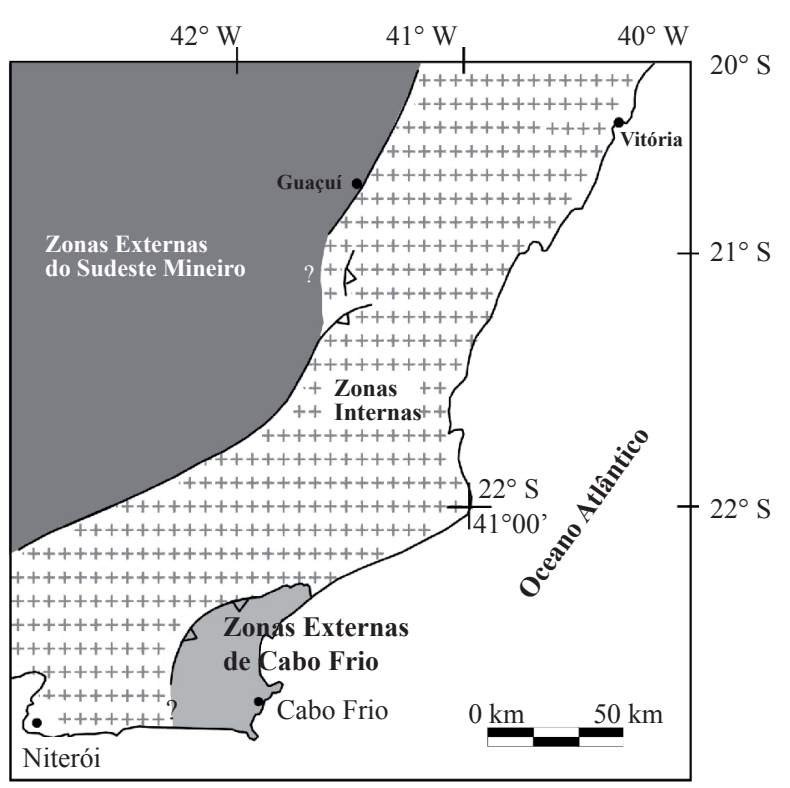

Figura 5 - As três zonas de Orógeno.

trabalho e é representada pelo Grupo Andrelândia, o qual é constituído, essencialmente, por rochas pelítico-psamíticas, que se estendem para o sul modificando sua paragênese metamórfica pelo desparecimento de cianita e presença de sillimanita e granada ao sul de Bom Jardim de Minas (Fonseca et al.). A segunda, sem designação formal, fica imediatamente ao norte da ZCRPS e ganha extensão considerável a SW de Leopoldina nas regiões de Bicas, Mar de Espanha, 
Pequeri, adentrando-se pelo território fluminense e representa, provavelmente, o flanco norte da estrutura em - flor - positiva, gerada pela transpressão entre os dois blocos crustais que formaram a ZCRPS, como proposto por Machado \& Endo (1993).

A terceira cobertura alóctone é representada por uma sequência de paragnaisses, que se situa no norte fluminense, entre as zonas de cisalhamento de São João do Paraíso e Bom Jesus de Itabapoana. Forma uma klippe, proveniente do leste, e estende-se até próximo à cidade de Bom Jesus de Itabapoana. É constituída por litotipos gnáissicos, sobretudo da Unidade Italva, mas foi, equivocadamente, atribuída por Fonseca et al. (1998) ao Complexo Paraíba do Sul. Ao sul de Itaperuna, existe também uma klippe, não dimensionada. As ZESM constituem, portanto, o domínio da aloctonia, ou seja, as sequências metassedimentares brasilianas nela existentes são alóctones.

As ZESM são muito pobres em corpos magmáticos brasilianos e quase todos estão situados próximos à ZS. Ao sul do paralelo 20, destaca-se o granitoide de Laginha e, no norte fluminense, os corpos granitoides de Varre-Sai, Itajara, Miracema, Morro do Côco e Valão do Bambuí. À exceção do primeiro, os outros são bem restritos (Quadro 1).

As Zonas Internas (ZI) também poderiam ser designadas de Zona Central, como no orógeno Limpopo. Nela, concentra-se a quase totalidade das rochas ortoderivadas brasilianas, além de granitoides do tipo $\mathrm{S}$ e diatexitos, por vezes muito extensos, e nela situa-se também o Arco Magmático Rio Negro.

Nesta zona encontram-se as duas mais extensas e importantes unidades metassedimentares do orógeno na região, que se apresentam muito distintas em sua paragênese metamórfica e em seu estilo estrutural. A primeira, a Unidade Italva, é composta por hornblenda-biotita gnaisses, mármores, anfibolitos, nos quais são relativamente frequentes sinformes e antiformes, colocados em evidência por Matos et al. (1980). A segunda, a Unidade São Fidélis, é uma sequência de gnaisses aluminosos, grossos, com ou sem cordierita, e calcissilicáticas, com migmatização acentuada, podendo passar a diversos tipos litológicos, com outras designações. Ocorrem nela, sobretudo, zonas de cisalhamento dúctil, entremeadas com corpos magmáticos de diversas suítes brasilianas; essa unidade está sempre ao leste da Unidade Italva, quando não empurradas para oeste.

No território capixaba, ao leste da ZCG, permanecem as mesmas disposições encontradas no território fluminense, existindo também cavalgamentos, que jogaram parte da Unidade São Fidélis para oeste, assim como se encontram lentes de metapsamitos, por vezes grossos, raramente encontrados no sul.

O segmento das Zonas Internas (ZI), que ficam ao sul da ZCRPS e a leste do meridiano da cidade do Rio de Janeiro, é, sob o ponto de vista estrutural e petrológico, uma das áreas mais complexas do orógeno. Tal segmento é constituído, em grande parte, pela unidade São Fidélis e suas variações. Apesar de nesta região existir uma orientação geral das estruturas segundo NE-SW, encontram-se numerosas escamas de cavalgamento, complexamente arranjadas, descontínuas e oblíquas entre si, colocadas em evidência por Grossi Sad \& Moreira (1978), Matos et al. (1980), Machado Filho et al. (1983).

Para sudoeste, diminui o grau metamórfico e as rochas metassedimentares formam vastíssimo conjunto, não separado, representado por uma grande variedade de litotipos, mas que mostram alguns parâmetros, definidos por Fonseca M.J.G. et al. (1998), tais como: "biotita como mineral máfico predominante, presença de sillimanita e granada, ausência de muscovita primária, e raro piroxênio, indicando que as condições de $\mathrm{P}$ e $\mathrm{T}$ ultrapassaram os limites de estabilidade da muscovita+quartzo, situando-se no grau alto de metamorfismo de Winkler (1977)". Mas, até bem próximo à Baía da Guanabara, aparecem isoladamente litotipos típicos do Complexo São Fidélis.

\begin{tabular}{|l|l|l|l|}
\hline PARÂMETROS & ZESM & ZI & ZECF \\
\hline Rochas Paleoproterozoicas & Aflorando extensivamente & Raríssimas & Aflorando extensivamente \\
\hline Magmatismo Brasiliano & $\begin{array}{l}\text { Raros corpos magmáticos } \\
\text { brasilianos }\end{array}$ & Concentração nesta zona & Ausente \\
\hline $\begin{array}{l}\text { Relação Embasamento / } \\
\text { Cobertura }\end{array}$ & Geralmente clara & Raríssima & Bem clara \\
\hline Fusão Crustal Brasiliana & Rara / restrita & $\begin{array}{l}\text { Intensa e extensa } \\
\text { Klipens e nappes para NW }\end{array}$ & $\begin{array}{l}\text { Cavalgamentos sinformes / } \\
\text { antiformes }\end{array}$ \\
\hline Principais estruturas & $\begin{array}{l}\text { Dispersão estrutural na } \\
\text { cobertura e no embasamento }\end{array}$ \\
\hline
\end{tabular}

Quadro 1 - Quadro comparativo das zonas do orógeno. 
Toda esta sequência, juntamente com as rochas ortoderivadas brasilianas, ocupa a quase totalidade da área das ZI, e se estende para o sudoeste, para além da cidade do Rio de Janeiro, sem qualquer descontinuidade. Assim, nas ZI, é muito difícil observar a relação embasamento/cobertura, como é comum nas duas outras zonas. Portanto, é desprovida de fundamento a afirmativa de Machado et al. (1996, p. 359) de que há predominância de rochas do embasamento em todos os domínios do orógeno, para justificar uma suposta evolução ensiálica do mesmo.

As Zonas Externas de Cabo Frio (ZECF) são constituídas por um embasamento de ortognaisses, de composição granítica à tonalítica, que passam a migmatitos homogêneos e heterogêneos, de melanossoma tonalítico, designados de Complexo Região dos Lagos. Sobre ele, encontram-se duas sequências metassedimentares distintas, as unidades Búzios e Palmital. As datações radiométricas do embasamento forneceram sempre idades paleoproterozoicas.

As ZECF caracterizam-se por: a) contraste litológico nítido entre seu embasamento e as duas unidades metassedimentares brasilianas superpostas; b) grande dispersão das direções estruturais no embasamento e na cobertura metassedimentar; c) ausência de corpos magmáticos brasilianos de caráter regional; d) desenvolvimento de uma sequência metassedimentar pelítica, de paragênese metamórfica de pressão intermediária a alta, a Unidade Búzios, e de outra, a Unidade Palmital, de paragênese metamórfica distinta da anterior: (gr)-sill-bi-kfd-pg gnaisse, que é a continuidade das rochas associadas ao Complexo São Fidélis.

As ZECF estendem-se da região de Macaé para o sudoeste. Seus limites com as ZI são claros apenas em raros pontos, como logo ao norte de Casimiro de Abreu, onde Fonseca et al. (1998) identificaram uma nappe do embasamento sobre as rochas metassedimentares brasilianas. A continuidade deste contato foi observada por Almeida et al. (2002) na Serra das Pedrinhas e do Segredo, na região a oeste de Macaé.

A grande dispersão das direções das estruturas planares e lineares, no embasamento e nas rochas supracrustais das ZECF, é inusitada, pois concentra-se mais na orla litorânea, e a única grande estrutura no embasamento é um megassinforme, de flancos suaves, de aproximadamente $10 \mathrm{~km}$ de extensão, e eixo orientado NW-SE, que ocupa boa parte da extremidade sudeste da região (Fonseca et al. 1998).

Quanto à Unidade Búzios, seu arcabouço e a dispersão de seus parâmetros estruturais não comportam paralelismo com os de qualquer outra unidade da região. As dobras são de dimensões decimétricas a métricas, fechadas a isoclinais, geralmente anisópacas, de charneiras agudas ou arredondadas, apresentam-se sempre inclinadas ou deitadas, e seus eixos mergulham para NNE ou SSW. Certamente, tal unidade foi formada e deformada em um ambiente bem restrito, diferente daquele que formou e deformou as outras unidades da região. Assim, não existem dados que justifiquem a interpretação de Heilbron et al. (1991) de que as Unidade Búzios e Italva teriam se formado juntas em uma bacia de retroarco.

Nossa discordância se dá pelas seguintes razões: 1) as duas unidades, Búzios e Italva, são separadas por um mínimo de $75 \mathrm{~km}$ e entre elas há uma extensíssima sequência brasiliana, dominantemente da Unidade São Fidélis, não devidamente separada, além de grande abundância de corpos magmáticos brasilianos, pós e sintectônicos; 2) as duas unidades exibem paragênese metamórfica muito diferentes, assim como são também distintos seus estilos estruturais; 3) dever-se-ia também explicar como se enquadraria a Unidade São Fidélis, que, na região, é bem extensa e se situa entre as duas unidades referidas.

Fonseca (1993) sugere que "os metassedimentos da região de Búzios fazem pressupor um ambiente de sedimentação de bordo de uma bacia de profundidade relativamente rasa e fluxo energético baixo, onde foram depositados os sedimentos pelíticos, psamíticos e carbonáticos”. Assim, a Unidade Búzios parece ter se formado em um ambiente de retroarco, mas sem a Unidade Italva.

No que diz respeito ao enquadramento tectônico das ZECF, os dados de campo convergem sistemática e claramente para a conclusão de que na região de Cabo Frio não houve qualquer convergência de placas posterior à orogênese brasiliana, como proposto por Schmitt (2001). Isto já foi extensivamente abordado por Fonseca (2003). Cita-se aqui apenas três razões: 1) as ZECF são destituídas de qualquer suíte, série ou associação magmática que possa caracterizar uma orogênese posterior à brasiliana na região; 2) sob o ponto de vista tectônico, não se pode identificar uma zona de cisalhamento que acompanhe integralmente o limite entre os dois blocos, não havendo como se reconhecer na região uma $\mathrm{ZS}$, que separaria dois orógenos distintos; 3 ) o embasamento paleoproterozoico das ZECF se estende para oeste até a região de Maricá, nas praias de Jaconé e Ponta Negra, a menos de $30 \mathrm{~km}$ da Baía de Guanabara, e é 
sobreposto pela Unidade Palmital, que é a continuidade, com pequenas modificações, da Unidade São Fidélis.

Rocha (2002), que mapeou em detalhe a região de Maricá, relata não ter encontrado nesta região a zona de cisalhamento que deveria necessariamente representar o 'contato' entre as ZECF, situadas a leste, e as sequências supracrustais brasilianas a noroeste.

É evidente que um conjunto de datações radiométricas pode definir um evento tectônico, mas não pode, por si só, determinar uma orogênese, pois este termo implica necessariamente o desenrolar de um processo complexo e de longa duração, cuja abrangência não pode ser alcançada senão com dados consistentes, que contemplem um espaço de tempo geológico não restrito. Orogênese implica, ainda, na criação de uma série de processos e feições no terreno, que devem ser claramente demonstrados, e sem os quais não se pode afirmar sua existência.
Sendo a anatexia e a formação de rochas granitoides dois dos principais processos que levam à diferenciação da crosta continental, é natural que as ZI sejam consideradas como a zona principal do orógeno, pois representa a parte mais transformada, espessa e profunda da cadeia em que se situou seu eixo térmico. Além disso, é a única que sofreu exclusivamente metamorfismo tipo Abukuma, enquanto as duas outras zonas sofreram metamorfismo de tipos Abukuma e Barroviano, em menor extensão e intensidade.

AGRADECIMENTOS Os autores agradecem ao Geólogo Eurípedes Pallazzo Silva, Presidente da Fundação Victor Dequech, pelo fato de ter tornado possível a análise dos ETR, no Laboratório LakefieldGeosol, sem qualquer ônus financeiro aos autores. Especial agradecimento ao revisor da RBG Ginaldo Campanha por sugestões e críticas ao manuscrito.

\section{Referências}

Almeida F.F.M., Amaral G., Cordani U.G., Kawashita K. 1973. The Precambrian evolution of the south american cratonic margin south of Amazon River. In: Nairn E.M. \& Stehli F.G. 1973. The ocean basins and margins. New York, Plenun., 1:411-446.

Almeida F.F.M., Hasui Y., Carneiro C.D.R. 1975. Lineamento de Além Paraíba. Anais da Academia Brasileira de Ciências, 47(3/4):575.

Almeida J.C.H., Dios F., Souza M.P.G. 2002. O contato entre os terrenos Cabo Frio e Costeiro na Faixa Ribeira Central. In: Congresso Brasileiro de Geologia, 41, João Pessoa, Anais, p. 287.

Batista J.J., Gomes B.S., Marchetto C.M.L. 1977. Folha Italva. Projeto Carta Geológica do Estado do Rio de Janeiro. DRM/Triservice, Rio de Janeiro, v. 1, Relatório Final.

Brandalise L.A., Ribeiro J.H., Ferrari P.G. 1976. Projeto Vale do Paraíba do Sul, Relatório Final. Convênio DNPM/CPRM, Belo Horizonte, 411 p.

Brenner T.L., Ferrari A.L., Penha H.M. 1980. Lineamentos estruturais do nordeste do Estado do Rio de Janeiro. In: XXXI Congresso Brasileiro de Geologia, Balneário Camboriú. Anais, 6:2551-2559.

Campanha G.A.C. 1980. O lineamento de Além Paraíba na área de Três Rios (RJ). Tese de Mestrado, Instituto de Geociências, Universidade de São Paulo, São Paulo, 109 p.

Campos Neto \& Figueiredo M.C.H. 1990. Evolução Geológica dos terrenos Costeiro, Paraíba do Sul e Juiz de Fora,Natal. In: XXXIV Congresso Brasileiro de Geologia. Anais, 6:2631-2642.
Carneiro J.T.G., Anísio L.C.C., Dayan H. 1996. Caracterização petrográfica e metamórfica de um segmento da zona de cisalhamento do rio Paraíba do Sul, nas cercanias de Além Paraíba, MG. In: XXXIX Congresso Brasileiro de Geologia, Salvador, Anais, 2:354-357.

Coleman R.G. 1977. Ophiolites, Ancient Oceanic Lithosphere? Springer-Verlag, Berlin, Heidelberg, New York, 203 p.

Cordani U.G., Delhal L., Ledent D. 1973. Orogénèses superposées dans le précambrian du Brésil sud-oriental (États de Rio de Janeiro et Minas Gerais). Revista Brasileira de Geociências, 3:1-22.

CPRM-COMPANHIA DE PESQUISAS DE RECURSOS MINERAIS. 1978. Projeto Aerogeofísica São PauloRio de Janeiro.

Corrêa Neto A.V. \& Dayan H. 1994. Justaposição de rochas de níveis crustais distintos em faixas transpressivas: o caso da zona de cisalhamento do Rio Paraíba do Sul, (RJ). In: XXXVIII Congresso Brasileiro De Geologia. Balneário Camboriú. Boletim de Resumos Expandidos, 1:249-250.

Dayan H. \& Keller J.V.A. 1990. A Zona de cisalhamento do rio Paraíba do Sul nas vizinhanças de Três Rios (RJ): uma análise da deformação dada por algumas feições estruturais. Revista Brasileira de Geociências, São Paulo, 19(4):494-506.

Dewey J.F. 1977. Suture zones complexities: a review. Tectonophysics, 40:53-70.

Ebert H. 1968. Ocorrência da fácies granulítica no sul de Minas Gerais e áreas adjacentes, em dependência 
da estrutura orogenética (hipótese sobre sua origem). Anais da Academia Brasileira de Ciências, 40(Supl):215-229.

Ebert H.D., Hasui Y., Costa J.B.S. 1991. O caráter transpressivo do Cinturão de Cisalhamento Rio Paraíba do Sul. In: III Simpósio Nacional de Estudos Tectônicos. SBG/SP, Boletim de Resumos Expandidos, Rio Claro, p. 139-141.

Fonseca A.C. 1993. Esboço Geocronológico da Região de Cabo Frio, Estado do Rio de Janeiro. Tese de Doutorado, Instituto de Geociências, Universidade de São Paulo, 158 p.

Fonseca M.J.G. 2003. Pegmatitos da parte centro leste do Estado do Rio de Janeiro e seu contexto tectônico. Tese de Doutorado, Instituto de Geociências, Universidade Federal do Rio de Janeiro, 211 p.

Fonseca M.J.G., Silva Z.C.G., Campos D.A., Tosatto P. 1979. Carta Geológica do Brasil ao Milionésimo (Folhas do Rio de Janeiro, Vitória e Iguape). Texto explicativo e mapa. DNPM, Brasília, 240 p.

Fonseca M.J.G., Peçanha R.M., Junho M.C.B., Francisco B.H.R., Dreher A. 1998. Mapa Geológico do Estado do Rio de Janeiro, escala 1:400.000 e texto correspondente. Programa cartas de Síntese - DNPM/ MME, Rio de Janeiro, 141 p.

Heilbron M., Valeriano C.M., Almeida J.C.H., Tupinambá M. 1991. A megassinforma do Paraíba do Sul e sua implicação na compartimentação tectônica do setor central da Faixa Ribeira. In: Atas II Simpósio de Geologia Sudeste, SBG/SP-RJ, São Paulo, p. 519-527.

Grossi Sad J.H. \& Moreira D. 1978. Geologia e Recursos minerais da Folha Santa Maria Madalena, Estado do Rio de Janeiro. Projeto Carta Geológica do Estado do Rio de Janeiro. Relatório Final, DRM/Geosol, Niterói, RJ, 282 p.

Lamego A.R. 1936. O maciço de Itatiaia e regiões circundantes. Boletim do Serviço Geológico e Mineralógico/ DNPM, Rio de Janeiro, p. 88-93.

Machado Filho L., Ribeiro M.W., Gonzales S.R., Schemini C.A., Santos Neto A., Palmeira R.C., Pires J.L., Teixeira W., Castro H.E. 1983. Geologia das Folhas do Rio de Janeiro e Vitória (SF 23/24), escala 1:1.000.000, mapa e texto explicativo, RADAM-Brasil, MME, Rio de Janeiro, 780 p.

Machado N., Valladares C.S., Heilbron M., Valeriano C. 1996. U/PB Geochronology of the central Ribeira belt: implications for the evolution of the Brazilian orogeny. Precambrian Research, 79:347-361.

Machado R. \& Endo I. 1993. A megaestrutura em flor positiva do vale do rio Paraíba do Sul no Rio de Janeiro e suas implicações tectônicas regionais. In: Sociedade Brasileira de Geologia, Simpósio Geológico do Sudeste, Atas, 1:208-213.

Matos G.M.M., Ferrari P.G., Cavalcanti J.C. 1980. Projeto Faixa Calcárea Cordeiro-Cantagalo. Folhas Cantagalo, Cordeiro, Quartéis. Relatório Final, texto, mapas. CPRM/DNPM. Belo Horizonte, 620 p.

Mendes J.C., Fonseca M.J., Moura J.C. 2011. Petrografia e geoquímica de rochas metamáficas e metaultramáficas da região de Cambuci, Rio de Janeiro. Anuário do Instituto de Geociências - UFRJ, 34(1):22-32.

Oliveira M.A.F. 1983. As rochas granulíticas da Faixa Paraíba do Sul. Revista Brasileira de Geociências, 13:84-92.

Rocha F.P. 2002. Mapeamento geológico da região de Maricá, Estado do Rio de Janeiro. Dissertação de Mestrado, Instituto de Geociências, Universidade Federal do Rio de Janeiro, Rio de Janeiro, 89 p.

Schmitt R. 2001. A Orogenia Búzios, um evento tectonometamórfico cambro-ordoviciano caracterizado no domínio tectônico de Cabo Frio, Faixa Ribeira, sudeste do Brasil. Tese Doutorado, Instituto de Geociências, Universidade Federal do Rio de Janeiro, 264 p.

Tupinambá M., Trouw R.A.J. 1994. Evidências de evolução metamórfica e estrutural anterior à tectônica transpressiva na Faixa Ribeira. In: XXXVIII Congresso Brasileiro de Geologia, Boletim de Resumos Expandidos, p. 175.

Winkler H.G. 1977. Petrogênese das rochas metamórficas, Editora Edgard Blucher Ltda, Porto Alegre, p. 264.

Manuscrito ID 23256

Recebido em: 17/09/2011 Aprovado em: 07/03/2012 